\title{
Dimensional Analysis on the Evaporation and Condensation of Refrigerant R-134a in Minichannel Plate Heat Exchangers
}

Amir Jokar ${ }^{*}{ }^{(1)}$, Mohammad H. Hosni ${ }^{(2)}$, Steven J. Eckels ${ }^{(2)}$

1) School of Engineering and Computer Science, Washington State University Vancouver, Vancouver, WA 98686, U.S.A.

2) Mechanical and Nuclear Engineering Department, Kansas State University, Manhattan, KS 66506, U.S.A.

${ }^{*}$ Corresponding author. Tel.: +1 785 5325620; fax.: +1 7855326642.

E-mail address: jokar@vancouver.wsu.edu (A. Jokar). 


\begin{abstract}
Two-phase flow analysis for the evaporation and condensation of refrigerants within the minichannel plate heat exchangers is an area of ongoing research, as reported in the literatures reviewed in this article. The previous studies mostly correlated the two-phase heat transfer and pressure drop in these minichannel heat exchangers using theories and empirical correlations that had previously been established for two-phase flows in conventional macrochannels. However, the two-phase flow characteristics within micro/minichannels may be more sophisticated than conventional macrochannels, and the empirical correlations for one scale may not work for the other one. The objective of this study is to investigate the parameters that affect the two-phase heat transfer within the minichannel plate heat exchangers, and to utilize the dimensional analysis technique to develop appropriate correlations. For this purpose, thermo-hydrodynamic performance of three minichannel brazed-type plate heat exchangers was analyzed experimentally in this study. These heat exchangers were used as the evaporator and condenser of an automotive refrigeration system where the refrigerant R-134a flowed on one side and a 50\% glycol-water mixture on the other side in a counter-flow configuration. The heat transfer coefficient for the single-phase flow of the glycol-water mixture was first obtained using a modified Wilson plot technique. The results from the single-phase flow analysis were then used in the two-phase flow analysis, and correlations for the refrigerant evaporation and condensation heat transfer were developed. Correlations for the single-phase and two-phase Fanning friction factors were also obtained based on a homogenous model. The results of this study showed that the two-phase theories and correlations that were established for conventional macrochannel heat exchangers may not hold for the minichannel heat exchangers used in this study.
\end{abstract}

Keywords: Plate Heat Exchangers, Minichannels, Evaporation, Condensation, Refrigerant R-134a, Dimensional Analysis, Enhanced Heat Transfer, Wilson plot.

\title{
Nomenclature:
}

A: heat transfer surface area $\left(\mathrm{m}^{2}\right)$

$\mathrm{A}_{0}$ : minimum free flow open area between two neighboring plates $\left(\mathrm{m}^{2}\right)$

a: constant

b: constant

Bo: Boiling number

C: constant

$\mathrm{C}_{\mathrm{p}}$ : specific heat $(\mathrm{J} / \mathrm{kg} . \mathrm{K})$

$\mathrm{C}_{\mathrm{f}}$ : Fanning friction factor

$\mathrm{C}_{\mathrm{x}}$ : coefficient based on vapor quality

D: diameter (m)

$\mathrm{D}_{\mathrm{h}}$ : hydraulic diameter (taken as twice the mean plate spacing in PHEs) (m)

G: mass flux $\left(\mathrm{kg} / \mathrm{m}^{2} . \mathrm{s}\right)$

$\mathrm{H}$ : dimensionless parameter accounting for sub-cooling in the condensate film

h: heat transfer coefficient $\left(\mathrm{W} / \mathrm{m}^{2} . \mathrm{K}\right)$

$\mathrm{h}_{\mathrm{fg}}$ : is the latent heat ( unit )

i: enthalpy $(\mathrm{J} / \mathrm{kg})$

Ja: Jacob number

k: thermal conductivity (W/m. K)

L: plate length (m)

$\mathrm{M}$ : molecular weight ( $\mathrm{kg} / \mathrm{kmole})$

$\mathrm{N}$ : number of plates

$\mathrm{Nu}$ : Nusselt number

$\mathrm{p}$ : system pressure $(\mathrm{Pa})$

$\mathrm{P}_{\mathrm{co}}$ : corrugation pitch (m) 
Pr: Prandtl number

$\mathrm{q}^{\prime \prime}$ : heat flux $\left(\mathrm{W} / \mathrm{m}^{2}\right)$

Re: Reynolds number

St: Stanton number

$\mathrm{T}$ : temperature $\left({ }^{\circ} \mathrm{C}\right)$

$\mathrm{U}$ : overall heat transfer coefficient $\left(\mathrm{W} / \mathrm{m}^{2} . \mathrm{K}\right)$

u: flow velocity $(\mathrm{m} / \mathrm{s})$

$\mathrm{x}$ : vapor quality

$\mathrm{X}_{\mathrm{tt}}$ : Lockhart-Martinelli parameter

\section{Greek Symbols:}

$\beta$ : plate corrugation inclination angle (deg.)

$\Delta \mathrm{p}$ : refrigerant frictional pressure drop $(\mathrm{Pa})$

$\Delta \mathrm{T}$ : temperature difference $\left({ }^{\circ} \mathrm{C}\right)$

$\Phi_{1}$ : two-phase friction multiplier

$\mu$ : dynamic viscosity (Pa.s)

$\rho$ : density $\left(\mathrm{kg} / \mathrm{m}^{3}\right)$

$\sigma:$ surface tension $(\mathrm{N} / \mathrm{m})$

\section{Subscripts:}

con: convective

cr: critical

eq: equivalent values

f: frictional

film: film condensation

g: glycol

gr: gravitational

h: hydraulic

l: liquid

LM: Logarithmic mean

m: mean values

man: manifold

ncb: nucleate boiling

p: plate

pool: pool boiling

$r$ r refrigerant

sat: saturation

sub: sub-cooled

sup: superheat

sp: single-phase

t: thickness

tot: total

tp: two-phase

wall: at wall condition

\section{Literature review}


The minichannel brazed-plate heat exchangers used in this study are a type of plate heat exchangers (PHEs) with corrugated parallel plates attached to one another and fitted into a casing. The plates have a corrugation inclination angle of " $\beta$ " to the main flow direction. The parallel plates and the supporting endplates are brazed together in a vacuum furnace. The two neighboring corrugated plates make three dimensional minichannels that create highly turbulent flow and enhance the heat transfer capability per unit volume of heat exchanger.

The single-phase flow inside the PHEs has widely been studied over the years but much less attention has been given to the two-phase flow in these types of heat exchangers. Most previous studies dealt with liquidliquid flows in PHEs, as extensively analyzed and summarized by Shah and Focke [1], Thonon et al. [2], and Focke et al. [3]. Shah and Wanniarachchi [4] developed the theory of plate heat exchanger design, and Wanniarachchi et al. [5] tried to approximate and develop a set of general correlations for a single-phase flow in PHEs. Manglik and Muley [6] and Muley and Manglik [7,8] studied heat transfer and pressure drop of the single-phase flows in PHEs experimentally, for various plate corrugation inclination angles and the ratio of effective to projected surface area.

Claesson $[9,10]$ studied the thermo-hydrodynamics of brazed plate heat exchangers. He suggested a new correlation for adiabatic pressure drop based on the Lockhart-Martinelli approach. The boiling heat transfer coefficient was also determined by the author, and the results were plotted versus mass flux and heat flux to investigate the importance of the two parameters. Heat flux was found to be more significant than mass flux in correlating the data.

Ayub [11] presented an extensive literature review for PHEs. The author also proposed the following heat transfer and pressure drop correlations for the evaporation of ammonia and refrigerant R-22 in direct expansion and flooded evaporators:

$$
\left\{\begin{array}{l}
\mathrm{h}_{\mathrm{tp}}=\mathrm{C}\left(\frac{\mathrm{k}_{1}}{\mathrm{D}_{\mathrm{e}}}\right)\left[\frac{\mathrm{Re}_{1}^{2} \mathrm{i}_{\mathrm{fg}}}{\mathrm{L}_{\mathrm{p}}}\right]^{0.4124}\left(\frac{\mathrm{p}}{\mathrm{p}_{\mathrm{cr}}}\right)^{0.12}\left(\frac{65}{\beta}\right)^{0.35} \\
\mathrm{C}=0.1121 \text { for flooded and thermo - syphon } \\
\mathrm{C}=0.0675 \text { for direct exp ansion (DX) }
\end{array}\right.
$$

This correlation is not dimensionless, and the values are based on English units. Ayub [11] also presented the evaporation pressure drop using the Fanning friction factor definition:

$$
\left\{\begin{array}{lc}
C_{f, t p}=\left(\frac{n}{R^{m}}\right)\left(-1.89+6.56 R-3.69 R^{2}\right) & {[30 \leq \beta \leq 65]} \\
R=(30 / \beta) & R e \leq 4,000 \\
\mathrm{~m}=0.137, n=2.99 & 4,000 \leq \mathrm{Re} \leq 8,000 \\
\mathrm{~m}=0.172, \mathrm{n}=2.99 & 8,000 \leq \mathrm{Re} \leq 16,000 \\
\mathrm{~m}=0.161, \mathrm{n}=3.15 & 16,000 \leq \mathrm{Re} \\
\mathrm{m}=0.195, \mathrm{n}=2.99 &
\end{array}\right.
$$

Ouazia [12] experimentally investigated heat transfer and pressure drop of refrigerant R-134a for the upward flow boiling inside a typical plate heat exchanger. The test configuration included three sets of plates with chevron angles of $0^{\circ}, 30^{\circ}$, and $60^{\circ}$. The author proposed a heat transfer correlation based on the ratio of the two-phase and single-phase heat transfer coefficients as follows:

$$
\mathrm{F}=\frac{\mathrm{h}_{\mathrm{tp}}}{\mathrm{h}_{1}}
$$

where the single-phase liquid heat transfer coefficient $\left(\mathrm{h}_{\mathrm{l}}\right)$ is calculated as: 


$$
\mathrm{h}_{1}=\mathrm{a} \frac{\mathrm{k}_{1}}{\mathrm{D}_{\mathrm{h}}}\left\{\frac{\mathrm{G}(1-\mathrm{x}) \mathrm{D}_{\mathrm{h}}}{\mu_{1}}\right\}^{\mathrm{b}} \operatorname{Pr}_{1}^{1 / 3}\left(\frac{\mu_{1}}{\mu_{\text {wall }}}\right)^{0.17}
$$

The constant "a" and "b" for the three corrugation angles were presented in Ouazia [12]. The factor $\mathrm{F}$ is a function of the Lockhart-Martinelli parameter $\left(\mathrm{X}_{\mathrm{tt}}\right)$, presented in Collier and Thome [13], and is obtained by the following equation:

$$
\mathrm{F}=1+\mathrm{C}_{1}\left(\frac{1}{\mathrm{X}_{\mathrm{tt}}}\right)^{\mathrm{C}_{2}}
$$

where,

$$
\frac{1}{X_{\mathrm{tt}}}=\left(\frac{\mathrm{x}}{1-\mathrm{x}}\right)^{1-\frac{\mathrm{n}}{2}}\left(\frac{\rho_{\mathrm{l}}}{\rho_{\mathrm{v}}}\right)^{0.5}\left(\frac{\mu_{\mathrm{v}}}{\mu_{1}}\right)^{\frac{\mathrm{n}}{2}}
$$

The constant " $\mathrm{C}_{1}$ " and " $\mathrm{C}_{2}$ " were determined and tabulated by Ouazia [12]. The author also correlated the refrigerant frictional pressure drop $\left(\Delta \mathrm{p}_{\mathrm{fr}}\right)$ within the corrugated plates using the two-phase friction multiplier:

$$
\Phi_{1}^{2}=\frac{\Delta \mathrm{p}_{\mathrm{fr}}}{\Delta \mathrm{p}_{1}}
$$

where the liquid pressure drop is obtained by:

$$
\Delta \mathrm{p}_{1}=\mathrm{C}_{\mathrm{f}, \mathrm{l}} \frac{2 \mathrm{~L}}{\mathrm{D}_{\mathrm{h}}} \frac{\mathrm{G}^{2}(1-\mathrm{x})^{2}}{\rho_{\mathrm{l}}}
$$

The two-phase friction multiplier " $\Phi_{1}$ ” is a function of the Lockhart-Martinelli parameter $\left(\mathrm{X}_{\mathrm{tt}}\right)$, defined by Equation (6), and given by:

$$
\Phi_{1}^{2}=1+\frac{\mathrm{C}}{\mathrm{X}_{\mathrm{tt}}}+\frac{1}{\mathrm{X}_{\mathrm{tt}}^{2}}
$$

Yan and Lin [14] considered the evaporation heat transfer and pressure drop of refrigerant R-134a in a PHE. They formed two vertical counter-flow channels in a heat exchanger using three plates of commercial geometry with a plate corrugation inclination angle of $\beta=60^{\circ}$. The up-flow boiling of refrigerant R-134a in one channel received heat from the hot down-flow of water in other channel. They explored the effect of mean vapor quality, mass flux, heat flux, and pressure of the refrigerant on the evaporation heat transfer and pressure drop. Using the Wilson plot technique, they first found a heat transfer correlation for the singlephase flow of water-to-water, given by:

$$
\mathrm{Nu}_{\mathrm{sp}}=0.2121 \operatorname{Re}^{0.78} \operatorname{Pr}^{1 / 3}\left(\frac{\mu_{\mathrm{m}}}{\mu_{\text {wall }}}\right)^{0.14}
$$

Yan and Lin [14] then correlated the evaporation heat transfer of refrigerant R-134a within the PHE with an average deviation of $8.3 \%$ as:

$$
\left\{\begin{array}{l}
\mathrm{Nu}_{\mathrm{tp}} \mathrm{Pr}_{1}^{-1 / 3} \mathrm{Re}_{1}^{0.5} \mathrm{Bo}_{\mathrm{eq}}^{-0.3}=1.926 \mathrm{Re}_{\mathrm{eq}} \\
2000<\mathrm{Re}_{\mathrm{eq}}<10,000
\end{array}\right.
$$

where the equivalents values first proposed by Akers [15], for mass flux, Reynolds number, and boiling number are:

$$
\left\{\begin{array}{l}
\mathrm{G}_{\mathrm{eq}}=\mathrm{G} \cdot \mathrm{C}_{\mathrm{x}} \\
\operatorname{Re}_{\mathrm{eq}}=\operatorname{Re}_{1} \cdot \mathrm{C}_{\mathrm{x}}=\mathrm{G}_{\mathrm{eq}} \mathrm{D}_{\mathrm{h}} / \mu_{1} \\
\mathrm{Bo}_{\mathrm{eq}}=\mathrm{Bo} / \mathrm{C}_{\mathrm{x}}=\mathrm{q}_{\mathrm{wall}}^{\prime \prime} / \mathrm{G}_{\mathrm{eq}} \mathrm{i}_{\mathrm{fg}}
\end{array}\right.
$$

The coefficient " $\mathrm{C}_{\mathrm{x}}$ " is a function of mean vapor quality $\left(\mathrm{x}_{\mathrm{m}}\right)$ and the liquid to vapor density ratio as: 


$$
C_{x}=\left(1-x_{m}\right)+x_{m}\left(\frac{\rho_{1}}{\rho_{g}}\right)^{0.5}
$$

Yan and Lin [14] also calculated the evaporation pressure drop of refrigerant R-134a and presented the Fanning friction factor with an average deviation of $7 \%$ as:

$$
\begin{cases}C_{f, t p} \operatorname{Re}^{0.5}=6.947 \times 10^{5} \operatorname{Re}_{\mathrm{eq}}^{-1.109} & \operatorname{Re}_{\mathrm{eq}}<6,000 \\ \mathrm{C}_{\mathrm{f}, \mathrm{pp}} \operatorname{Re}^{0.5}=31.21 \mathrm{Re}_{\mathrm{eq}}^{0.04557} & \operatorname{Re}_{\mathrm{eq}} \geq 6,000\end{cases}
$$

Hsieh and Lin [16] studied evaporation heat transfer and pressure drop of refrigerant R-410a flowing in a vertical PHE. They first obtained the single-phase water-to-water heat transfer coefficient based on the modified Wilson plot technique, given as:

$$
\mathrm{h}_{\mathrm{sp}}=0.2092\left(\frac{\mathrm{k}_{1}}{\mathrm{D}_{\mathrm{h}}}\right) \operatorname{Re}^{0.78} \operatorname{Pr}^{1 / 3}\left(\frac{\mu_{\mathrm{m}}}{\mu_{\text {wall }}}\right)^{0.14}
$$

An evaporation heat transfer correlation was also presented by the authors. This correlation considered the contribution due to both convection and nucleation, given by:

$$
h_{\mathrm{tp}}=\text { E. } \mathrm{h}_{1}+\text { S.h } \mathrm{h}_{\text {pool }} \quad\left\{\begin{array}{c}
2000<\mathrm{Re}<12,000 \\
0.0002<\mathrm{Bo}<0.0020
\end{array}\right.
$$

where the liquid heat transfer coefficient " $h$ " was obtained from the Dittus-Boelter equation:

$$
\mathrm{h}_{1}=0.023 \operatorname{Re}_{1}^{0.8} \operatorname{Pr}^{0.4}\left(\mathrm{k}_{1} / \mathrm{D}_{\mathrm{h}}\right)
$$

and the two-phase pool boiling heat transfer coefficient was obtained from the Cooper equation:

$$
\mathrm{h}_{\text {pool }}=55 \mathrm{P}_{\mathrm{r}}^{0.12}\left(-\log _{10} \mathrm{P}_{\mathrm{r}}\right)^{-0.55} \mathrm{M}^{-0.5} \mathrm{q}^{\prime \prime 0.67}
$$

The factors " $\mathrm{E}$ " and "S" represented the enhancement and suppression, respectively, and were given by:

$$
\mathrm{E}=1+24,000 \mathrm{Bo}^{1.16}+1.37\left(\frac{1}{\mathrm{X}_{\mathrm{tt}}}\right)^{0.86}
$$

and,

$$
\mathrm{S}=\left(1+1.15 \times 10^{-6} \mathrm{E}^{2} \mathrm{Re}_{1}^{1.17}\right)^{-1}
$$

The Lockhart-Martinelli parameter $\left(\mathrm{X}_{\mathrm{tt}}\right)$ was defined by Equation (6), and boiling number was defined by Equation (12). Hsieh and Lin [16] also proposed the following correlation for the two-phase friction factor as:

$$
\mathrm{f}_{\mathrm{tp}}=23,820 \operatorname{Re}_{\mathrm{eq}}^{-1.12} \quad\left\{\begin{array}{c}
2000<\mathrm{Re}<12,000 \\
0.0002<\mathrm{Bo}<0.0020
\end{array}\right.
$$

The equivalent mass flux and Reynolds number were defined by Equations (12) a and (12)b, respectively.

Han et al. [17] performed experiments on the evaporation of refrigerants R-410a and R-22 in PHEs with the plate corrugation inclination angles of $45^{\circ}, 35^{\circ}$, and $20^{\circ}$. They proposed the following correlation for Nusselt number:

$$
\mathrm{Nu}_{\mathrm{tp}}=\mathrm{Ge}_{1} \mathrm{Re}_{\mathrm{eq}}^{\mathrm{Ge}_{2}} \mathrm{Bo}_{\mathrm{eq}}^{0.3} \mathrm{Pr}^{0.4}
$$

where,

$$
\mathrm{Ge}_{1}=2.81\left(\frac{\mathrm{P}_{\mathrm{co}}}{\mathrm{D}_{\mathrm{h}}}\right)^{-0.041}\left(\frac{\pi}{2}-\beta\right)^{-2.83}
$$

and,

$$
\mathrm{Ge}_{2}=0.746\left(\frac{\mathrm{p}_{\mathrm{co}}}{\mathrm{D}_{\mathrm{h}}}\right)^{-0.082}\left(\frac{\pi}{2}-\beta\right)^{0.61}
$$

They also proposed a correlation for the friction factor, as: 


$$
\mathrm{f}_{\mathrm{tp}}=\mathrm{Ge}_{3} \mathrm{Re}_{\mathrm{eq}}{ }^{\mathrm{Ge}_{4}}
$$

where,

$$
\mathrm{Ge}_{3}=64,710\left(\frac{\mathrm{p}_{\mathrm{co}}}{\mathrm{D}_{\mathrm{h}}}\right)^{-5.27}\left(\frac{\pi}{2}-\beta\right)^{-3.03}
$$

and,

$$
\mathrm{Ge}_{4}=-1.314\left(\frac{\mathrm{p}_{\mathrm{co}}}{\mathrm{D}_{\mathrm{h}}}\right)^{-0.62}\left(\frac{\pi}{2}-\beta\right)^{-0.47}
$$

where the equivalent Reynolds and Boiling numbers were obtained by Equations (12)b and (12)c, respectively.

Kedzierski [18] studied the effect of inclination on the performance of PHEs as the evaporators and condensers. Additional studies on the evaporation within the PHEs include Jonsson [19], Clausen [20], Brotherton [21], Talik et al. [22], and Corberan and Gonzalvez [23].

A literature review showed that even fewer studies have been done on the condensation within PHEs than on the evaporation. Panchal [24] obtained the overall heat transfer coefficient and pressure drop for the condensation of ammonia in PHEs with different plate corrugation inclination angles. Arman and Rabas [25] presented a theoretical analysis to predict single component and binary-mixture condensation in plate-frame heat exchangers.

Wang et al. [26] obtained pressure drop characteristics of complete and partial condensation in a PHE. They found that during steam condensation in the PHE, the flow was always turbulent, and that the condensate film flow was laminar at first, changing to turbulent flow very quickly in the wavy channel. The Reynolds number of the condensate flow at exit ranged from 800 to 1800, where the flow was fully turbulent. The average difference between calculated and experimental values was $12 \%$.

Wang and Zhao [27] analyzed the condensation heat transfer and pressure drop of steam in PHEs. They accounted for the condensate flow, steam content, condensation temperature difference, and pressure to formulate a correlation as follows:

$$
\mathrm{Nu}_{\mathrm{tp}}=0.00115\left(\frac{\mathrm{Re}_{1}}{\mathrm{H}}\right)^{0.983}\left(\operatorname{Pr}_{1}\right)^{0.33}\left(\frac{\rho_{\mathrm{l}}}{\rho_{\mathrm{v}}}\right)^{0.248}
$$

where " $\mathrm{H}$ " is a dimensionless parameter accounting for sub-cooling in the condensate film, defined by:

$$
\mathrm{H}=\frac{\mathrm{C}_{\mathrm{p}}\left(\mathrm{T}_{\text {sat }}-\mathrm{T}_{\text {wall }}\right)}{\mathrm{i}_{\mathrm{fg}}\left(1+0.68 \mathrm{C}_{\mathrm{p}}\left(\mathrm{T}_{\text {sat }}-\mathrm{T}_{\text {wall }}\right) / \mathrm{i}_{\mathrm{fg}}\right)}
$$

Longo et al. [28] recently presented the heat transfer coefficients for vaporization and condensation of refrigerant R-22 in PHEs with a plate corrugation inclination angle of $65^{\circ}$. They presented experimental data for both evaporation and condensation and reported that the surface enhancements in PHEs, compared to a smooth surface, cause an increase in heat transfer rate up to $40 \%$ for the vaporization, and to $60 \%$ for the condensation. Jokar et al. [29, 30] reported on condensation and evaporation of refrigerant R-134a in PHEs with a plate corrugation inclination angle of $60^{\circ}$.

Studies reviewed above correlated the evaporation and condensation heat transfer and pressure drop within PHEs using theories and empirical correlations that had previously been established for two-phase flows in conventional macrochannels. However, the two-phase flows within the three-dimensional corrugated minichannels of PHEs may be more sophisticated than the smooth circular and non-circular macrochannels. In other words, the empirical correlations developed for macro-scale systems may not work for micro/miniscale systems. The influence of certain variables on evaporation and condensation may also change in the micro/mini-scale. For example, surface tension is a variable that is more important on the micro/mini-scale than on the macro-scale. However, this effect was largely ignored by most of the studies reviewed above.

In the current study, dimensional analysis is used as a tool to evaluate and develop correlations for the evaporation and condensation. Each variable included in the correlation must be critically evaluated, and 
proper consideration must be given to the dimensionless term used. Experimental data were obtained for three brazed-plate heat exchangers with similar interior plate design but different number of plates. These PHEs were used as the evaporator and condenser of an automotive compression refrigeration system that was tested under a wide range of operating conditions.

\section{Experimental test facility}

A schematic diagram of the experimental apparatus used in this study is shown in Fig. 1.

The system consists of a main refrigeration loop using R-134a, two 50\% glycol -water mixture loops, and two air loops for cooling and heating.

\subsection{Main refrigeration loop}

The main refrigeration loop included an evaporator, a condenser, a compressor, and an expansion valve. Thermocouples and pressure transducers were installed at the inlet and outlet ports of all components to measure temperature and pressure. A Coriolis-effect flow meter was used to measure the refrigerant mass flow rate, which was controlled by varying the compressor speed using a frequency controlled AC motor. The refrigerant charge was varied for each test condition to control the sub-cooled temperature at the condenser exit and the superheat temperature at the evaporator exit. Two secondary fluid systems (glycolwater mixture) were designed to exchange energy with the evaporator and the condenser.

\subsection{Plate heat exchangers}

Three PHEs of different sizes (i.e, 34, 40, and 54 plates) were used as the evaporator and condenser of the system. The geometry and size information of the PHEs used in this study are summarized in Table 1.

The flow configuration of the PHE interior plates is illustrated in Fig. 2. Two separate vertical passages on either side of each plate allow the secondary fluid and the refrigerant to flow between every other plate and provide a complete separation of the fluids. The uniquely designed geometry of the corrugated plates creates high turbulence and pressure drop. The flows of the refrigerant and glycol-water mixture are both single-pass, which creates a counter-flow configuration, as shown in Fig. 2 . The heat exchangers were completely insulated to minimize the heat loss from the case and the connecting pipes.

\subsection{Data acquisition}

Monitoring and controlling the system variables, such as temperatures, pressures, and flow rates, required developing an automated data acquisition and control unit for the entire system. For this purpose, two multichannel data acquisition and control units with 6 1/2 digits resolution were used. The data acquisition system included input and output boards and a power supply. The measured voltages were monitored by a voltmeter and switch unit, and after being processed, they were displayed on the computer screen.

\subsection{Test procedure}

The system was set up for a particular test, and a range of test conditions was used to obtain adequate experimental data. The system variables, such as temperatures, pressures, and flow rates, were recorded every 10 seconds as raw data. Once the fluctuations in glycol-water mean temperatures within the system became stable (within $\pm 1^{\circ} \mathrm{C}$ ), the system was considered to be at a steady state condition. Data collection then began and continued for at least 10 minutes for each test condition. The data collected during the 10 minutes period were averaged and used for analysis.

\section{Calculation method and data reduction}

After the experimental data were collected, a semi-empirical technique was used to obtain heat transfer and pressure drop correlations for the single-phase and two-phase flows within the PHEs under study. 


\subsection{Single-phase heat transfer analysis}

The modified Wilson plot technique, introduced by Briggs and Young [31], was applied to determine the single-phase heat transfer correlation for the PHEs in this study. Details of this analysis were previously reported in Jokar et al. [29].

It is important to introduce the definition of the Reynolds number for the thermal/fluid analysis of PHEs. This dimensionless parameter is defined as:

$$
\operatorname{Re}=\frac{D_{h} G}{\mu}
$$

where the hydraulic diameter is defined as twice the mean plate spacing. As discussed by Shah and Wanniarachchi [4], the mass flux is calculated by dividing the mass flow rate to the minimum free flow open area between the parallel plates. The interior flow pattern of the PHEs is three-dimensional and can not be estimated by simple flow between vertical parallel plates. The flow between the plates is neither vertical nor parallel. In fact, by attaching the plates together, some three-dimensional tube-shape passages are created through which the fluid flows. In this study, the minimum free flow open area $\left(A_{0}\right)$, between two neighboring plates, was estimated as:

$$
\mathrm{A}_{\mathrm{o}}=\frac{3}{2} \pi \mathrm{D}_{\mathrm{h}}^{2}
$$

\subsection{Single-phase pressure drop analysis}

The single-phase frictional pressure drop was calculated by subtracting the inlet/outlet manifold and gravitational pressure drop from the total pressure drop:

$$
\Delta \mathrm{P}_{\mathrm{f}}=\Delta \mathrm{P}_{\text {tot }}-\Delta \mathrm{P}_{\mathrm{gr}}-\Delta \mathrm{P}_{\text {man }}
$$

The gravitational pressure drop was zero for this analysis because the total pressure drop from inlet to

outlet port of the PHEs was measured by a differential pressure transducer installed in the middle height of the heat exchanger. The manifold pressure drop at the inlet and outlet ports was estimated using empirical correlations, such as the one introduced by Shah and Wanniarachchi [4]. This pressure drop was approximated as 1.5 times the inlet velocity head:

$$
\Delta \mathrm{P}_{\text {man }}=1.5\left[\frac{\rho \mathrm{u}_{\mathrm{m}}^{2}}{2}\right]_{\mathrm{in}}
$$

The Fanning friction factor for the single-phase flow was then calculated based on the Fanning equation as:

$$
\mathrm{C}_{\mathrm{f}, \mathrm{sp}}=\Delta \mathrm{P}_{\mathrm{f}} \frac{\mathrm{D}_{\mathrm{h}}}{\mathrm{L}_{\mathrm{p}}} \frac{\rho_{\mathrm{m}}}{2 \mathrm{G}^{2}}
$$

This variable was calculated for each single test, and an appropriate correlation was then obtained for the best curve fitted through the collected experimental data.

\subsection{Two-phase heat transfer coefficient}

The evaporator in this study was divided into two different regions: a two-phase evaporation region and a single-phase superheat region. The condenser had the same two regions and a single-phase sub-cooled region. The evaporation and condensation temperature diagrams are shown in Fig. 3.

The rate of heat transfer from both refrigerant and glycol sides were carefully calculated to check the amount of heat loss through the heat exchanger case. This energy loss may affect the system overall thermal efficiency. However, it should not affect the calculations of the two-phase heat transfer coefficients since the energy balance from inlet to outlet ports on the refrigerant side only, , was used. The glycol-water temperatures corresponding to the saturated points in refrigerant side (i.e., $\mathrm{T}_{\mathrm{g}, \text { sup }}$ and $\mathrm{T}_{\mathrm{g}, \mathrm{sub}}$ ), as shown in Fig. 3 ., were also calculated using an average energy balance on the refrigerant and glycol side. This temperature was typically calculated for the evaporator by the following equation: 


$$
\mathrm{T}_{\mathrm{g}, \text { sup }}=\mathrm{T}_{\mathrm{g}, \text { in }}-\left(\frac{\dot{\mathrm{m}}_{\mathrm{r}}\left(\mathrm{i}_{\mathrm{r}, \text { out }}-\mathrm{i}_{\mathrm{r} \text {,sat-vap }}\right)}{\dot{\mathrm{m}}_{\mathrm{g}} \mathrm{C}_{\mathrm{pg}}}\right)
$$

Next, the logarithmic mean temperature difference in single-phase regions (i.e., superheated or sub-cooled) were calculated using the following equation:

$$
\Delta \mathrm{T}_{\mathrm{LM}}=\frac{\Delta \mathrm{T}_{1}-\Delta \mathrm{T}_{2}}{\operatorname{Ln}\left(\frac{\Delta \mathrm{T}_{1}}{\Delta \mathrm{T}_{2}}\right)}
$$

where the temperature difference ( $\Delta \mathrm{T})$ was typically calculated for the evaporation as:

$$
\begin{aligned}
& \Delta \mathrm{T}_{1}=\mathrm{T}_{\mathrm{g}, \text { in }}-\mathrm{T}_{\mathrm{r}, \text { out }} \\
& \Delta \mathrm{T}_{2}=\mathrm{T}_{\mathrm{g}, \text { sup }}-\mathrm{T}_{\mathrm{r}, \text { sat-vap }}
\end{aligned}
$$

The overall heat transfer coefficient for this region was calculated as:

$$
\frac{1}{\mathrm{U}_{\text {sup }}}=\frac{1}{\mathrm{~h}_{\mathrm{g}, \text { sup }}}+\frac{1}{\mathrm{~h}_{\mathrm{r}, \text { sup }}}+\left(\frac{\mathrm{t}}{\mathrm{k}}\right)_{\text {wall }}
$$

where " $\mathrm{h}_{\mathrm{g}, \text { sup }}$ " and " $\mathrm{h}_{\mathrm{r}, \text { sup }}$ " are calculated from the single-phase heat transfer correlation developed by the Wilson plot technique. The heat transfer surface area of the single-phase regions, e.g., super-heated region in evaporator, was then calculated as:

$$
\mathrm{A}_{\text {sup }}=\frac{\dot{\mathrm{m}}_{\mathrm{r}}\left(\mathrm{i}_{\mathrm{r}, \text { out }}-\mathrm{i}_{\mathrm{r}, \text { sat }-\mathrm{v}}\right)}{\mathrm{U}_{\text {sup }} \cdot \Delta \mathrm{T}_{\mathrm{LM}, \text { sup }}}
$$

The heat transfer surface area of the two-phase saturation region $\left(A_{\text {sat }}\right)$ was calculated by subtracting the single-phase region surface areas from the total surface area of the PHE, e.g., for the evaporator, as:

$$
A_{\text {sat }}=(N-2) A_{p}-A_{\text {sup }}
$$

The overall heat transfer coefficient of the two-phase saturation region was then calculated by:

$$
\mathrm{U}_{\text {sat }}=\frac{\dot{\mathrm{m}}_{\mathrm{r}}\left(\mathrm{i}_{\mathrm{r}, \text { sat }-\mathrm{v}}-\mathrm{i}_{\mathrm{r}, \mathrm{in}}\right)}{\mathrm{A}_{\text {sat }} \cdot \Delta \mathrm{T}_{\mathrm{LM}, \text { sat }}}
$$

where " $\Delta \mathrm{T}_{\mathrm{LM}, \text { sat }}$ " was calculated by Equation (36) with the temperature differences defined (e.g., for the

evaporator) as:

$$
\begin{aligned}
\Delta \mathrm{T}_{1} & =\mathrm{T}_{\mathrm{g}, \text { sup }}-\mathrm{T}_{\mathrm{r}, \text { sat-vap }} \\
\Delta \mathrm{T}_{2} & =\mathrm{T}_{\mathrm{g}, \text { out }}-\mathrm{T}_{\mathrm{r}, \text { sat-in }}
\end{aligned}
$$

The two-phase heat transfer coefficient of the refrigerant in the saturation region was finally calculated, based on the single-phase heat transfer coefficient, as:

$$
\frac{1}{\mathrm{~h}_{\text {sat }}}=\frac{1}{\mathrm{U}_{\text {sat }}}-\frac{1}{\mathrm{~h}_{\mathrm{g}, \text { sat }}}-\left(\frac{\mathrm{t}}{\mathrm{k}}\right)_{\text {wall }}
$$

Equation (43) was applied to each test point in the three PHEs to obtain the two-phase heat transfer coefficient. These data were then used to develop a two-phase heat transfer correlation using the dimensional analysis technique.

\subsection{Two-phase Fanning friction factor}

The procedure for calculating two-phase frictional pressure drop was similar to the single-phase flow analysis, except in addition to the manifold and gravitational pressure drops, the acceleration/deceleration and superheated/sub-cooled pressure drops included in total pressure drop calculation:

$$
\Delta \mathrm{P}_{\mathrm{f}}=\Delta \mathrm{P}_{\text {tot }} \pm \Delta \mathrm{P}_{\text {acc }}-\Delta \mathrm{P}_{\text {gr }}-\Delta \mathrm{P}_{\text {man }}-\Delta \mathrm{P}_{\text {sup }}-\Delta \mathrm{P}_{\text {sub }}
$$


The components of pressure drop in the above equation were estimated using the measured and calculated data. The details of these calculations were previously reported in Jokar et al. [29]. Equation (44) was then applied to all experiments to obtain the two-phase Fanning friction factor for the refrigerant flow in the evaporator and condenser as:

$$
\mathrm{C}_{\mathrm{f}, \mathrm{p}}=\Delta \mathrm{P}_{\mathrm{f}} \frac{\mathrm{D}_{\mathrm{h}}}{\mathrm{L}_{\mathrm{sat}}} \frac{\rho_{\mathrm{m}, \mathrm{sat}}}{2 \mathrm{G}^{2}}
$$

\subsection{Uncertainty of the measured and calculated parameters}

The measurement system in this study recorded temperatures, pressures, pressure differences, and mass flow rates for both the refrigerant and glycol-water mixture. An uncertainty analysis method, introduced by Coleman and Steele [32], was applied to all calculations to find the uncertainties on the single-phase and twophase heat transfer coefficients and Fanning friction factors. The single-phase uncertainty estimates of the pressure drop and heat transfer coefficients were significantly smaller than the two-phase estimates, as shown in Table 2.

The results of this analysis for the two-phase heat transfer coefficients of the refrigerant in the evaporator and condenser are shown in Fig. 4. This figure shows that the uncertainties were small at high mass flow rates, while they increased sharply with decreased flow rate. The propagation of uncertainty estimates showed that the uncertainty associated with absolute pressure measurement was the dominant uncertainty term. The test points with higher uncertainty were retained for the analysis because they contained valuable information about the effect of both temperature difference and mass flux. The two-phase flows within the evaporator and condenser are further explained in the result section.

\section{Results and discussion}

The results for the evaporation and condensation of R-134a through the PHEs are presented, plotted, and discussed in this section. Semi-empirical correlations are developed for the heat transfer coefficients using the dimensional analysis technique. The two-phase Fanning friction factors are also derived.

\subsection{Single-phase heat transfer and pressure drop correlations}

The single-phase heat transfer test was conducted with water flowing on one side of the PHEs and the $50 \%$ glycol-water mixture on the other side. The Wilson-plot procedure was then applied to the data set to determine the single-phase heat transfer correlation. The resulting correlation is given by:

$$
\mathrm{Nu}_{\mathrm{sp}}=0.089 \operatorname{Re}^{\mathrm{p}} \operatorname{Pr}^{\mathrm{n}}
$$

where $n=0.3$ for cooling and $n=0.4$ for heating. The Reynolds number exponent (p) that gave the minimum deviation in the Wilson plot was 0.79 for the glycol-water side. Based on a Chilton-Colburn analogy, at higher Reynolds numbers, the exponent "p" deviates from this value as the surface roughness causes the friction factor to be independent of Reynolds number. The average standard deviation (A.S.D.) between the experimental data and the above correlation was about 5\%, where A.S.D. was defined as:

$$
\text { A.S.D. }\left.\right|_{\mathrm{Nu}}(\%)=\frac{100}{\mathrm{n}} \cdot \sum_{1}^{\mathrm{n} \text { (tests) }}\left(\mathrm{ABS}\left|\frac{\mathrm{Nu}_{\text {Experiment }}-\mathrm{Nu}_{\text {Correlation }}}{\mathrm{Nu}_{\text {Experiment }}}\right|\right)
$$

The results showed that the heat transfer coefficient in the PHEs was high even at very low Reynolds numbers. This is a definite advantage that is gained from using this kind of heat exchanger, mostly caused by the enhanced heat transfer surface area in PHEs. The correlation given in Equation (46) compared well with similar studies on PHEs (within 10\% compared to the studies of Muley and Manglik [6,7,8]), as previously presented and explained in Jokar et al. [29].

Single-phase pressure drop correlation was also obtained for the PHEs under study using the Fanning equation. The resulting Fanning friction factor with a 17\% average standard deviation is given by: 


$$
\mathrm{C}_{\mathrm{f}, \mathrm{sp}}=6.431 \mathrm{Re}^{-0.25}
$$

The above correlation compared well with similar studies, as discussed in Jokar et al. [29].

\subsection{Two-phase heat transfer correlation equation}

The data collected from the experiments were used to calculate the two-phase heat transfer coefficient for each test point. A fundamental dimensional analysis was used to obtain the appropriate dimensionless terms for evaporation and condensation in PHEs. However, this approach has not often been used in other research.

Several major parameters accounted for the general two-phase heat transfer equation, including system geometry, refrigerant mass flow rate, refrigerant thermo-physical properties, refrigerant latent heat during phase change, temperature difference between the refrigerant and channel walls as a heat transfer driving force, buoyancy force due to the phase change, surface tension effect due to the small size of flow passages, and vapor quality if the evaporation or condensation are partial (incomplete). Some of these parameters, such as mass flow rate, are integrated within the convection term of evaporation and condensation heat transfer. Other parameters, such as latent heat or temperature difference, are integrated within the boiling or film condensation terms. These categorizations are discussed more in detail later in this section.

At least 12 independent variables were found to be important for correlating the two-phase flows within the PHEs under study, as listed in the following equation:

$$
\mathrm{f}\left(\mathrm{h}_{\mathrm{tp}}, \mathrm{G}, \mathrm{D}_{\mathrm{h}}, \Delta \mathrm{T}_{\mathrm{r}-\text { wall }}, \mathrm{i}_{\mathrm{fg}}, \mu_{1}, \mathrm{C}_{\mathrm{p}, \mathrm{l}}, \mathrm{k}_{\mathrm{l}}, \rho_{\mathrm{l}}, \rho_{\mathrm{l}}-\rho_{\mathrm{v}}, \sigma, \mathrm{x}\right)=0
$$

The plate corrugation inclination angle, which is an important geometrical parameter for the analysis of PHEs, is missing from the above equation because all the heat exchangers under study had the same plate corrugation inclination angle of $60^{\circ}$.

Equation (49) consists of 12 independent variables with four primary dimensions involved (i.e., $\mathrm{kg}[\mathrm{M}], \mathrm{m}[\mathrm{L}], \mathrm{s}[\mathrm{T}]$, and $\mathrm{K}[\theta]$ ). Therefore, the total numbers of dimensionless parameters that should be included in the analysis is eight. The following repeating variables were selected for this analysis to make sure all four major dimensions are involved.

$$
\mathrm{D}_{\mathrm{h}}[\mathrm{L}], \mu_{1}\left[\mathrm{ML}^{-1} \mathrm{~T}^{-1}\right], \mathrm{C}_{\mathrm{p}, \mathrm{l}}\left[\mathrm{L}^{2} \mathrm{~T}^{-2} \theta^{-1}\right], \rho_{1}\left[\mathrm{ML}^{-3}\right]
$$

These four variables should then be integrated with each non-repeating variable introduced in Equation (49) to form a system of dimensionless parameter. The results of dimensional analysis for the specified variables are in the following form:

$$
\mathrm{F}\left(\Pi_{\mathrm{i}}\right)=0 \quad(\mathrm{i}=1 \text { to } 8)
$$

where:

$$
\begin{aligned}
& \Pi_{1}=\frac{\mathrm{h}_{\mathrm{tp}} \mathrm{D}_{\mathrm{h}}}{\mathrm{k}_{\mathrm{l}}}=\mathrm{Nu}_{\mathrm{tp}}, \Pi_{2}=\frac{\mathrm{GD}_{\mathrm{h}}}{\mu_{1}}=\operatorname{Re}_{1}, \Pi_{3}=\frac{\mathrm{C}_{\mathrm{p}, 1} \mu_{1}}{\mathrm{k}_{1}}=\operatorname{Pr}_{1} \\
& \Pi_{4}=\mathrm{x}, \Pi_{5}=\frac{\mathrm{G}^{2}}{\rho_{1}^{2} \mathrm{C}_{\mathrm{p}, 1} \Delta \mathrm{T}}, \Pi_{6}=\frac{\rho_{\mathrm{l}}^{2} \mathrm{i}_{\mathrm{fg}}^{\prime}}{\mathrm{G}^{2}}, \Pi_{7}=\frac{\rho_{\mathrm{l}} \sigma}{\mu_{\mathrm{l}} \mathrm{G}}, \Pi_{8}=\frac{\rho_{\mathrm{l}}}{\rho_{\mathrm{l}}-\rho_{\mathrm{v}}}
\end{aligned}
$$

Combining the dimensionless parameters may form other pre-defined dimensionless numbers. For example, combining $\Pi_{5}$ and $\Pi_{6}$ will form the Jacob number (Ja) or Boiling number (Bo). The vapor quality (x) defined in Equation (49) presents a dimensionless parameter by itself. However, other forms of dimensionless parameters can be used, such as Equation (13) which combined the vapor quality with the liquid to vapor density ratio. Mean vapor quality $\left(\mathrm{x}_{\mathrm{m}}\right)$ is used in this study since the evaporation is incomplete. The refrigerant thermodynamic properties were evaluated at the film temperature between the refrigerant and channel wall. The wall temperature can be calculated from an energy balance on the glycolwater side using the calculated single-phase heat transfer coefficient.

An appropriate mathematical function should be fitted through the experimental data to obtain the minimum standard deviation. Such a function, of course, should comply with the common understanding of 
the fundamentals for two-phase flows. This analysis was done, and the resulting evaporation and condensation correlations are presented in the next sections.

\subsection{Evaporation heat transfer correlation results}

For evaporation heat transfer, two main effects should be considered in correlating the Nusselt number: the forced convective term ( $\left.\mathrm{Nu}_{\text {con }}\right)$ and the nucleate boiling term $\left(\mathrm{Nu}_{\text {ncb }}\right)$. Chen [33] introduced a model that superimposes these two effects, now known as the Chen correlation. However, the summation of the two terms did not work well for the experimental results in this study. Other mathematical combinations were investigated to find the minimum average standard deviation (A.S.D.) between the experimental data and the correlations, as defined by Equation (47). The following correlation was thus proposed for the evaporation of refrigerant R-134a within the PHEs, using the dimensionless parameters defined in Equation (52), with an A.S.D. of about $31 \%$ :

$$
\mathrm{Nu}_{\mathrm{tp}}=0.603 \operatorname{Re}_{1}^{0.5} \operatorname{Pr}_{1}^{0.1} \mathrm{x}^{-2}\left(\frac{\mathrm{G}^{2}}{\rho_{1}^{2} \mathrm{C}_{\mathrm{p}, \mathrm{l}} \Delta \mathrm{T}}\right)^{-0.1}\left(\frac{\rho_{\mathrm{l}}^{2} \mathrm{i}_{\mathrm{fg}}^{\prime}}{\mathrm{G}^{2}}\right)^{-0.5}\left(\frac{\rho_{\mathrm{l}} \sigma}{\mu_{\mathrm{l}} \mathrm{G}}\right)^{1.1}\left(\frac{\rho_{\mathrm{l}}}{\rho_{\mathrm{l}}-\rho_{\mathrm{v}}}\right)^{2}
$$

Note that in some cases when the exponents of the dimensionless parameters are the same, combining these terms can simplify the correlation. For example, combining $\Pi_{5}$ and $\Pi_{6}$ in Equation (52) yields:

$$
\Pi_{5} \Pi_{6}=\frac{\mathrm{i}_{\mathrm{fg}}^{\prime}}{\mathrm{C}_{\mathrm{p}, \mathrm{l}} \Delta \mathrm{T}}=\frac{1}{\mathrm{Ja}}
$$

where "Ja", the Jacob number, is the ratio of sensible to latent energy absorbed during liquid-vapor phase change. This dimensionless number can be replaced by boiling number, which is sometime used in correlating evaporation, such as the Yan and Lin [14] correlation in Equation (11). The Jacob number and boiling number are related by the following relationship:

$$
\text { Bo }=\text { JaSt }
$$

where "St", the Stanton number, is a modified Nusselt number and defined as:

$$
\mathrm{St}=\frac{\mathrm{Nu}}{\mathrm{RePr}}
$$

The proposed correlation for Nusselt number in Equation (53) was compared to the experimental results, as shown in Fig. 5. The deviation between the proposed correlation and the experimental results shows satisfactory agreement for typical two-phase flows.

An extensive literature search showed only a few studies reporting correlations for the evaporation of refrigerants in PHEs. The results of this study thus have some unique aspects because the refrigerant mass flow rate through the PHEs and, as a result, the Reynolds numbers are low. The refrigeration system was less stable at low Reynolds numbers, so the system temperatures fluctuated more during experiments.

The experimental results of this study can be compared to the two-phase evaporation heat transfer correlation introduced by Yan and Lin [14], as presented in Equation (11). The experimental test points have been plotted and then compared with the Yan and Lin [14] correlation in Fig. 6.

Fig. 6 shows a plot of dimensionless parameters based on the left-hand side of Equation (11) versus the equivalent Reynolds number, as presented by Yan and Lin [14]. There is a difference between the results of this study and those of Yan and Lin [14], as seen in Fig. 6. They studied the partial evaporation of refrigerant R-134a with small increments for vapor quality in a PHE with a specific plate geometry, while in this study, the evaporation took place over a wide quality difference between inlet and outlet ports (from about 0.4 to 1 ). The experimental data in this study included both evaporation and superheated regions, so the single-phase superheated region was subtracted from the experimental data and used for the absolute two-phase region.

The equivalent Reynolds number for the experiments in this study varied from 450 to 3400, while the Reynolds number varied from 70 to 440 . At low Reynolds numbers, the effect of temperature difference between the refrigerant and channel wall becomes more important, while at higher Reynolds numbers, the 
convection heat transfer becomes more effective. A mix of these two effects was observed for most test points in this study.

\subsection{Condensation heat transfer correlation}

For condensation heat transfer, the same methodology was applied to find the two-phase heat transfer correlation. Two mechanisms accounted for correlating the condensation Nusselt number: forced convection heat transfer $\left(\mathrm{Nu}_{\text {con }}\right)$ and film condensation $\left(\mathrm{Nu}_{\text {film }}\right)$. Several mathematical combinations were investigated to find the minimum average standard deviation (A.S.D.) between the experimental data and the correlations. The following correlation, including all the variables introduced in Equation (49), is thus proposed:

$$
\mathrm{Nu}_{\mathrm{tp}}=3.371 \operatorname{Re}_{1}^{0.55} \operatorname{Pr}_{1}^{0.3}\left(\frac{\mathrm{G}^{2}}{\rho_{1}^{2} \mathrm{C}_{\mathrm{p}, \mathrm{l}} \Delta \mathrm{T}}\right)^{1.3}\left(\frac{\rho_{1}^{2} \mathrm{i}_{\mathrm{fg}}^{\prime}}{\mathrm{G}^{2}}\right)^{1.05}\left(\frac{\rho_{1} \sigma}{\mu_{1} \mathrm{G}}\right)^{0.05}\left(\frac{\rho_{1}}{\rho_{1}-\rho_{\mathrm{v}}}\right)^{2}
$$

where the average standard deviation (A.S.D.) between the experimental data and correlation was about $6 \%$. The coefficient for the vapor quality $\left(\mathrm{C}_{4}\right)$ was zero because the condensation process in this study was not partial but complete. In some cases when the exponents of the dimensionless parameters are the same, combining these terms can simplify the correlation. For example, multiplying $\Pi_{5}$ and $\Pi_{6}$ in Equation (52) yields the Jacob number "Ja", as presented by Equation (54) for the evaporator analysis. The Jacob number, in this case, is the ratio of sensible to latent energy released during liquid-vapor phase change. This dimensionless number is the same as dimensionless parameter " $\mathrm{H}$ " in Wang and Zhao [27] correlation, as shown in Equation (29).

The calculated two-phase Nusselt number from Equation (57) was compared to the experimental results in Fig. 7. The deviation between the proposed correlation and the experimental results is even better than the deviations obtained for the evaporation process.

There have been few studies on condensation in PHEs. The correlation proposed for steam condensation by Wang and Zhao [27], Equation (28), was compared with the results of this study as shown in Fig. 8.

Figure 8 is a plot of the dimensionless parameters introduced in Wang and Zhao [27], as presented in Equation (28). The difference between the results of this study and Wang and Zhao [27] may be explained by differences in geometry and patterns of the interior corrugated plates in the PHEs. Furthermore, Wang and Zhao [27] studied the condensation of steam in a refrigeration pump system, while in this study, the refrigerant R-134a was used as the working fluid for a compression refrigeration loop. The experimental data in this study included condensation, sub-cooled regions, and superheated regions, so the single-phase subcooled and super-heated regions were subtracted from the experimental data for the absolute two-phase region.

Note that several two-phase flow patterns are involved in the thermal performance of the PHEs, especially at low and transitional Reynolds numbers. For some data points, the film condensation is the dominant effect on heat transfer, especially where temperature differences are small, while at high mass flow rate, convection is more important.

\subsection{Two-phase pressure drop correlations}

Several different models were examined for analyzing the two-phase pressure drop of the refrigerant within the evaporator. The Lockhart-Martinelli and the Martinelli-Nelson models, introduced by Collier and Thome [13], were applied to estimate frictional pressure drop in this study, but none of them were suitable. The homogenous model best described the experimental results in this study.

Correlating the Fanning friction factor was attempted based on the hydrodynamic parameters of the heat exchanger (i.e., Reynolds number). As a result, the following correlation was best fitted through all the experimental data with a $50 \%$ A.S.D.: 


$$
\mathrm{C}_{\mathrm{f}, \mathrm{pp}}=5.474 \times 10^{3}\left(\frac{\mathrm{GD}_{\mathrm{h}}}{\mu_{\mathrm{l}}}\right)^{-1.35} \quad 70 \leq \frac{\mathrm{GD}_{\mathrm{h}}}{\mu_{\mathrm{l}}} \leq 420
$$

Equation (58) does not account for the effect of refrigerant vapor quality at the evaporator inlet port. Yan and Lin [14] took the mean vapor quality into account for partial evaporation in a PHE, as shown in Equation (14) . If the same analysis is applied to the experiential results of this study, a similar correlation is derived:

$$
\mathrm{C}_{\mathrm{f}, \mathrm{p}} \mathrm{Re}_{1}^{0.35}=3.521 \times 10^{4} \mathrm{Re}_{\mathrm{eq}}^{-1} \quad 440 \leq \mathrm{Re}_{\mathrm{eq}} \leq 3,200
$$

The last correlation can be rewritten in terms of Reynolds number and the mean vapor quality:

$$
\mathrm{C}_{\mathrm{f}, \mathrm{tp}}=3.521 \times 10^{4} \mathrm{Re}_{1}^{-1.35} \mathrm{C}_{\mathrm{x}}^{-1} \quad 70 \leq \mathrm{Re}_{1} \leq 420
$$

where $C_{x}$ was previously defined by Equation (13). This correlation showed about $46 \%$ A.S.D. Equation (60) is now comparable with Equation (58) in that it is a simpler correlation based on Reynolds number only. The experimental results and the proposed correlation, Equation (59) or (60), are compared in Fig. 9.

Figure 9 shows relatively large variations between the experimental results and the correlation. The twophase flow pattern for evaporation inside the PHEs is very complex and the flow inside PHEs is threedimensional through corrugated channels. In fact, the two attached corrugated plates make a series of parallel 3-D channels with variable cross sectional areas along the flow.

Like the evaporator analysis, the homogenous model best described the experimental results for condensation in the PHEs. The following correlation was best fitted through all the experimental data with a 51\% A.S.D.:

$$
\mathrm{C}_{\mathrm{f}, \mathrm{tp}}=2.139 \times 10^{7}\left(\frac{\mathrm{GD}_{\mathrm{h}}}{\mu_{\mathrm{m}, \mathrm{sat}}}\right)^{-1.6} \quad 960 \leq \frac{\mathrm{GD}_{\mathrm{h}}}{\mu_{\mathrm{m}, \mathrm{sat}}} \leq 4,160
$$

where the average viscosity, defined in Collier and Thome [13], for the mean vapor $\left(\mathrm{x}_{\mathrm{m}}\right)$ is calculated as:

$$
\frac{1}{\mu_{\mathrm{m}, \mathrm{sat}}}=\frac{\mathrm{x}_{\mathrm{m}}}{\mu_{\text {sup }}}+\frac{1-\mathrm{x}_{\mathrm{m}}}{\mu_{\text {sub }}}
$$

The experimental results and the proposed correlation, Equation (61), are compared in Fig. 10.

There were large variations between the experimental results and the condensation correlation. As for evaporation, the flow pattern for the two-phase condensation inside the PHEs is very complex and difficult to describe. At low mass fluxes, the Reynolds number varies with quality and is likely transitioning from laminar to turbulent flow over the quality range. This complex feature makes it unlikely that a simple model, like the one shown in Equation (61), will account for all these changes.

\section{Summary and conclusions}

The literatures on evaporation and condensation of refrigerant R-134a in plate heat exchangers (PHEs) were reviewed first. Three different sizes of minichannel PHEs, with the same corrugated plate design were then studied experimentally. The thermo-hydrodynamic performance of these PHEs was analyzed, and their heat transfer and pressure drop were correlated using the dimensional analysis technique applied to both measured and calculated parameters. The PHEs in this study were used as the evaporator and the condenser of a standard compression refrigeration cycle. The entire refrigeration system was run at different operating conditions, and the required data, including temperatures, pressures, and mass flow rates were collected.

The single-phase flow for the PHEs was analyzed first, and pressure drop and heat transfer were correlated. The two-phase heat transfer and pressure drop for the refrigerant evaporation and condensation were then studied using single-phase results. As predicted, single-phase experimental results were easier to model than the two-phase flow results. The two-phase flow results had a relatively large spread. This large variation may be attributed to the complexity of the two-phase flow. This complexity is much more pronounced at small flow rates and low Reynolds numbers, because the corresponding experimental uncertainty becomes larger. 
The results of this study showed that the two-phase theories and correlations that have been established for the conventional macrochannel heat exchangers may not be directly applicable to the mini/micro-channel heat exchangers, such as the plate heat exchangers under study. It seems that the effects of variables involved in evaporation and condensation in micro/minichannels are different from those in macrochannels. For example, the refrigerant surface tension as a thermodynamic property might have a greater role in describing the phase change processes within the smaller heat exchangers.

Clearly more accurate and detailed work need to be done on two-phase flows within the micro/minichannel heat exchangers. The results of this study will be useful in this area since the experimental data were collected under actual industry-specified operating conditions.

\section{References}

1. R. K. Shah, W.W. Focke, Plate heat exchangers and their design theory, Heat Transfer Equipment Design, eds. (Shah, R.K., Subbarao, E.C., Mashelkar, R.A.), 227-254, Hemisphere Publishing, Washington, DC, 1988.

2. B. Thonon, R.Vidil, C. Marvillet, Recent research and developments in plate heat exchangers, Journal of Enhanced Heat Transfer 2, no. 1-2 (1995) 149-155.

3. W.W. Focke, J. Zachariades, I. Olivier, The effect of the corrugation inclination angle on the thermohydraulic performance ofpPlate heat exchangers, International Journal of Heat and Mass Transfer 28, no. 8 (1985) 1469-1479.

4. R.K. Shah, A.S. Wanniarachchi, Plate heat exchanger design theory, Industrial Heat Exchangers. Lecture Series \#1991-04, J.-M. Bushlin, ed., Von Karman Institute for Fluid Dynamics, Belgium, 1992.

5. A.S. Wanniarachchi, U. Ratnam, B.E. Tilton, K.D. Roy, Approximate correlations for chevron-type plate heat exchangers, Proceedings of the $30^{\text {th }}$ National Heat Transfer Conference, ASME-Heat Transfer Division, vol. 314, no. 12 (1995) 145-151.

6. R.M. Manglik, A. Muley, Thermal-hydraulic behavior of a mixed chevron single-pass plate-and-frame heat exchanger, Proceedings of the $30^{\text {th }}$ National Heat Transfer Conference, ASME-Heat Transfer Division, vol. 314, no. 12 (1995) 89-96.

7. A. Muley, R.M. Manglik, Enhanced heat transfer characteristics of single-phase flows in a plate heat exchangers with mixed chevron plates, Journal of Enhanced Heat Transfer 4, no. 3 (1997) 187-201.

8. A. Muley, R.M. Manglik, Experimental study of turbulent flow heat transfer and pressure drop in a plate heat exchanger with chevron plates, Journal of Heat Transfer (Transactions of the ASME) 121, no. 1 (1999) 110-117.

9. J. Claesson, Thermal and hydraulic characteristics of brazed plate heat exchangers-Part I: review of singlephase and two-phase adiabatic and flow boiling characteristics, ASHRAE Transactions 111, part 1, presented at the 2005 ASHRAE Winter Meeting, \#OR-05-10-2, 2005.

10. J. Claesson, Thermal and hydraulic characteristics of brazed plate heat exchangers-Part II: current research on evaporators at KTH, ASHRAE Transactions 111, part 1, presented at the 2005 ASHRAE Winter Meeting, \#OR-05-10-3, 2005.

11. Z.H. Ayub, Plate heat exchanger literature survey and new heat transfer and pressure drop correlations for refrigerant evaporators, Heat Transfer Engineering 24, no. 5 (2003) 3-16.

12. B. Ouazia, Evaporation heat transfer and pressure drop of HFC-134a inside a plate heat exchanger, Proceedings of American Society of Mechanical Engineers, Process Industries Division (PID), vol. 6 (2001) 115-123.

13. J.C. Collier, J.R. Thome, Convective boiling and condensation, $3^{\text {rd }}$ Edition, Oxford University Press, New York, 1994.

14. Y.Y. Yan, T.F. Lin, Evaporation heat transfer and pressure drop of refrigerant R-134a in a plate heat exchanger, Journal of Heat Transfer (Transaction of the ASME) 121, no. 1 (1999) 118-127.

15. W.W. Akers, H.A. Deans, O.K. Crosser, Condensation heat transfer within horizontal tubes, Chemical Engineering Progress 54 (1958) 89-90. 
16. Y.Y. Hsieh, T.F. Lin, Evaporation heat transfer and pressure drop of refrigerant R-410a flow in a vertical plate heat exchanger, Journal of Heat Transfer (Transactions of the ASME) 125, no. 5 (2003) 852857.

17. D.H. Han, K.J. Lee, Y.H. Kim, Experiments on the characteristics of evaporation of R-410A in brazed plate heat exchangers with different geometric configurations, Applied Thermal Engineering 23, no. 10 (2003) 1209-1225.

18. M.A. Kedzierski, Effect of inclination on the performance of a compact brazed plate condenser and evaporator, Heat Transfer Engineering 18, no. 3 (1997) 25-38.

19. I. Jonsson, Plate heat exchangers as vaporizers and condensers for refrigerants using liquid on the secondary side, Technical paper-AIRAH Tech'85 Conference, Melbourne, 1985.

20. N.E. Clausen, Development of a plate evaporator/condenser for the mechanical vapor compression process, Proceedings of the $12^{\text {th }}$ International Symposium on Desalination and Water Re-Use, Malta (1991) 399-406.

21. F. Brotherton, Evaporation in plate type heat exchangers, Heat Recovery Systems \& CHP 14, no. 5 (1994) 555-561.

22. A.C. Talik, L.S. Fletcher, N.K. Anand, L.W. Swanson, Heat transfer and pressure drop characteristics of a plate heat exchanger using a propylene-glycol/water mixture as the working fluid, Proceedings of the $30^{\text {th }}$ National Heat Transfer Conference, ASME-Heat Transfer Division, vol. 314, no. 12 (1995) 8388.

23. J.M. Corberan, J. Gonzalvez, Two-phase heat transfer analysis of evaporators, Experimental Thermal and Fluid Science 26, no. 2-4 (2002) 259-267.

24. C.B. Panchal, Condensation heat transfer in plate heat exchangers, Proceedings of the $23^{\text {rd }}$ National Heat Transfer Conference, ASME-Heat Transfer Division, vol. 44 (1985) 45-52.

25. B. Arman, T.J. Rabas, Condensation analysis for plate-frame heat exchangers, Proceedings of $30^{\text {th }}$ National Heat Transfer Conference, ASME-Heat Transfer Division, vol. 314, no. 12 (1995) 97-104.

26. L.K. Wang, B. Sundén, Q.S. Yang, Pressure drop analysis of steam condensation in a plate heat exchanger, Heat Transfer Engineering 20, no. 1 (1999) 71-77.

27. Z.Z. Wang, Z.N. Zhao, Analysis of performance of steam condensation heat transfer and pressure drop in plate condensers, Heat Transfer Engineering 14, no. 4 (1993) 32-41.

28. G.A. Longo, A. Gasparella, R. Sartori, Experimental heat transfer coefficients during refrigerant vaporization and condensation inside herringbone-type plate heat exchangers with enhanced surfaces, International Journal of Heat and Mass Transfer 47, no. 19-20 (2004) 4125-4136.

29. A. Jokar, S.J. Eckels, M.H. Hosni, T.P Gielda, Condensation heat transfer and pressure drop of the brazed plate heat exchangers using R-134a, Journal of Enhanced Heat Transfer 11, no 2 (2004) 161-182.

30. A. Jokar, S.J. Eckels, M.H. Hosni, Thermo-hydrodynamic of the evaporation of refrigerant R-134a in brazed plate heat exchangers, Proceedings of the 2004 ASME Heat Transfer/Fluids Engineering Summer Conference, CD-ROM, \#HT-FED04-56573, Charlotte, 2004.

31. D.E. Briggs, E.H. Young, Modified wilson plot techniques for obtaining heat transfer correlations for shell and tube heat exchangers, Chemical Engineering Progress Symposium, AIChE Heat TransferPhiladelphia, vol. 65, no. 92 (1969) 35-45.

32. H.W. Coleman, W.G. Steele, Experimentation and uncertainty analysis for engineers, $1^{\text {st }}$ Edition, John Wiley \& Sons, New York, 1989.

33. J.C. Chen, A correlation for boiling heat transfer to saturated fluids in convective flow, ASME preprint 63-HT-34, presented at $6^{\text {th }}$ National Heat Transfer Conference, Boston, 1963. 


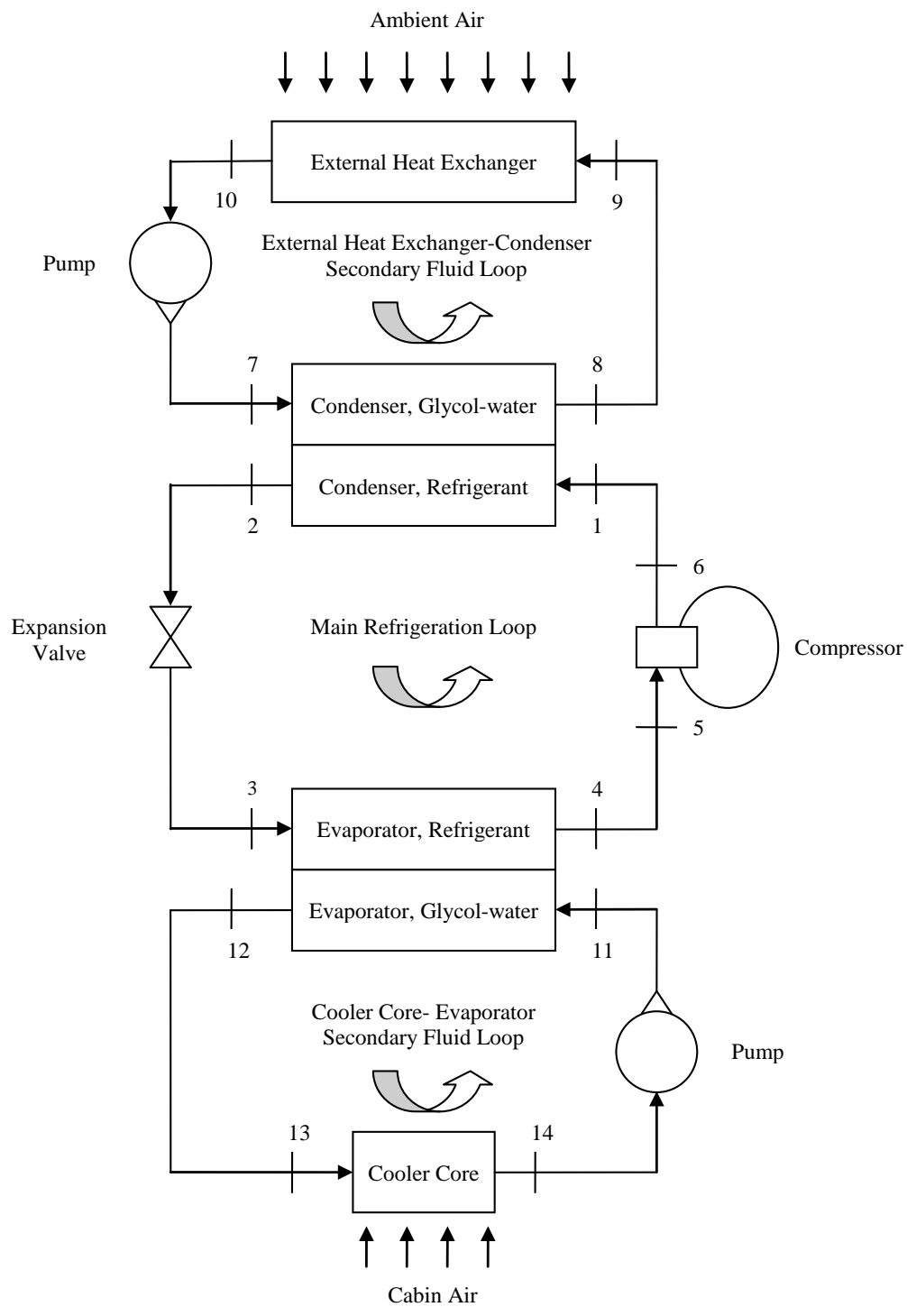

Fig. 1. Schematic diagram of the experimental test facility. 


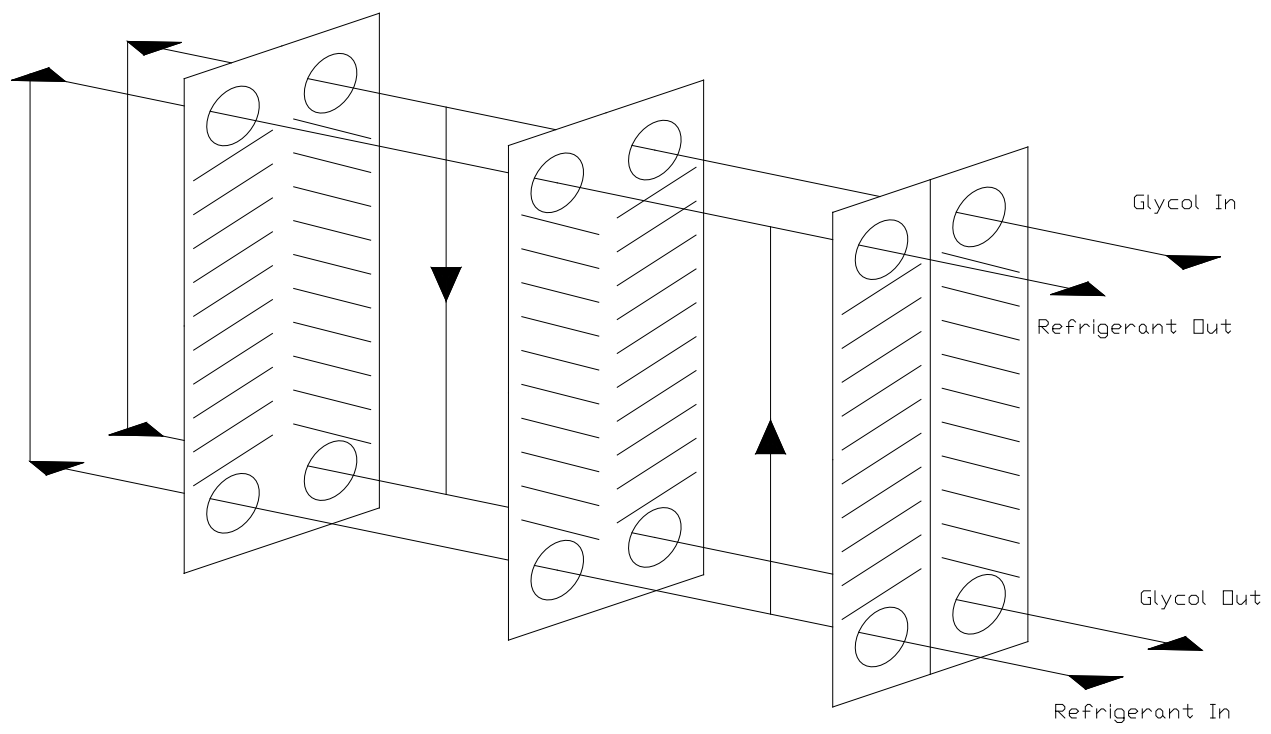

Fig. 2. Counter-flow configuration of the refrigerant and glycol-water mixture within the PHEs. 


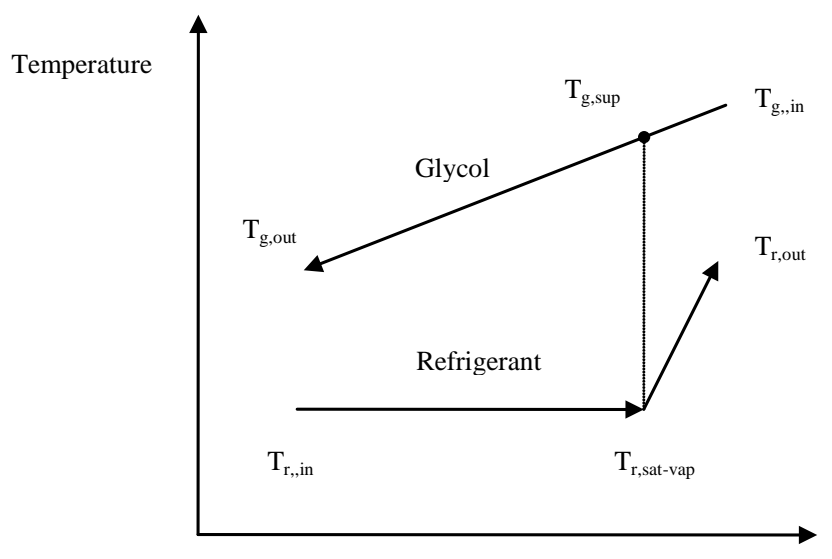

Flow Path in Evaporator

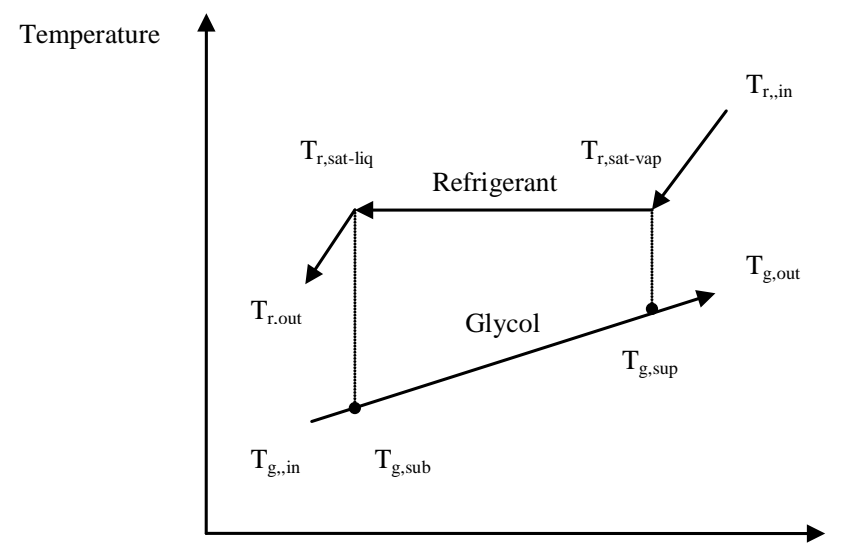

Flow Path in Condenser

Fig. 3. Temperature diagrams for the PHEs used as the evaporator and condenser. 


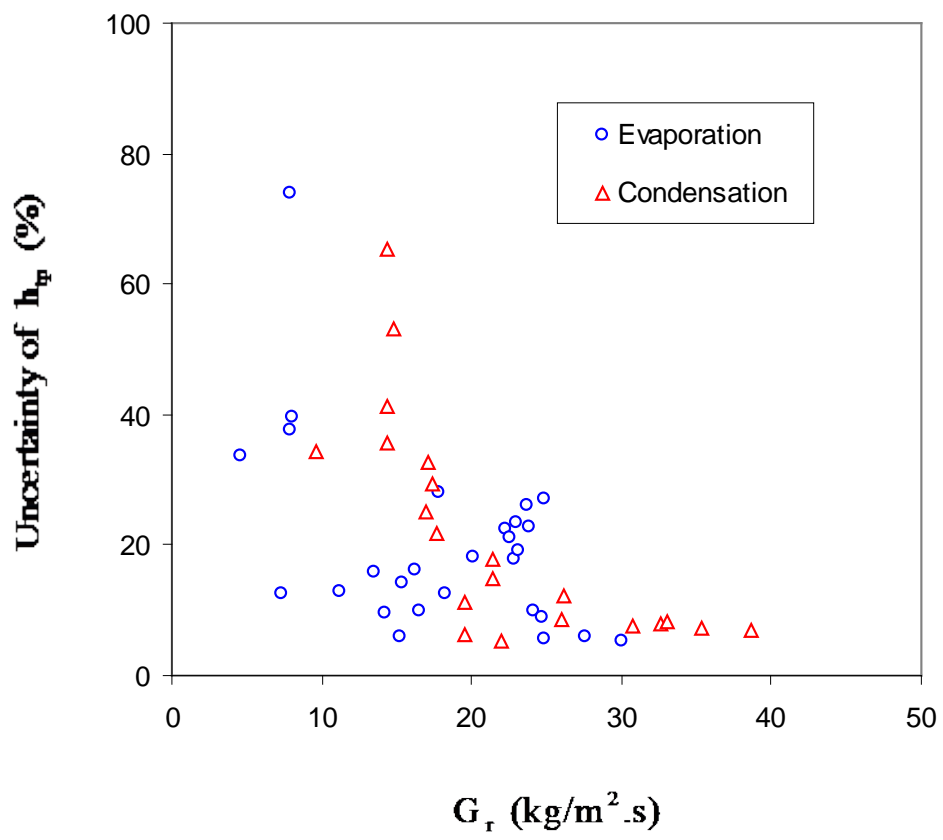

Fig. 4. Uncertainty of the two-phase heat transfer coefficients for the refrigerant evaporation and condensation.

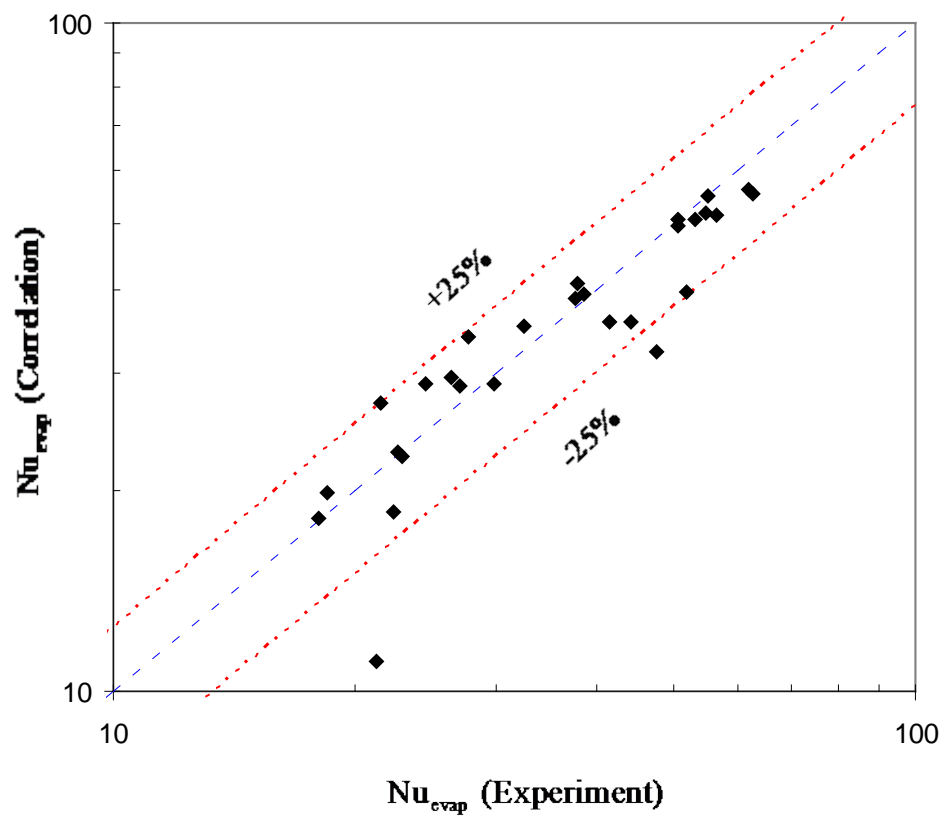

Fig. 5. Comparison between the experimental data and proposed correlation for the evaporation heat transfer of refrigerant R-134a in the PHEs. 


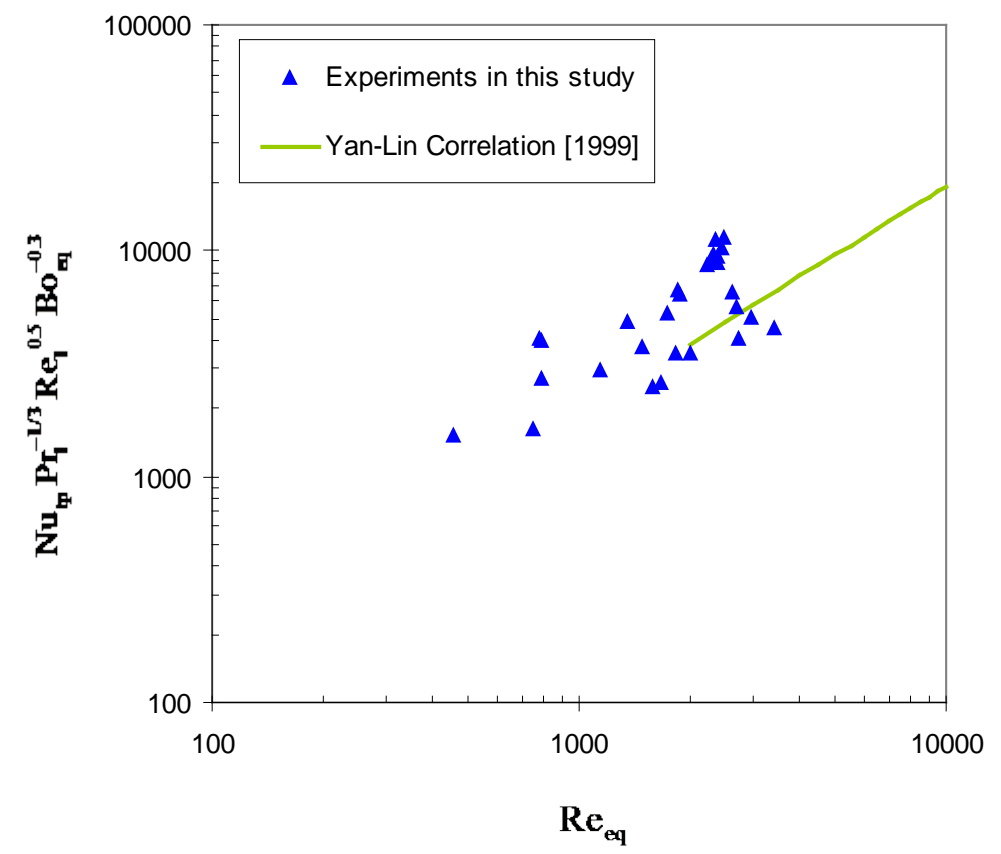

Fig. 6. Heat transfer correlations for the evaporation of refrigerant R-134a in the PHEs.

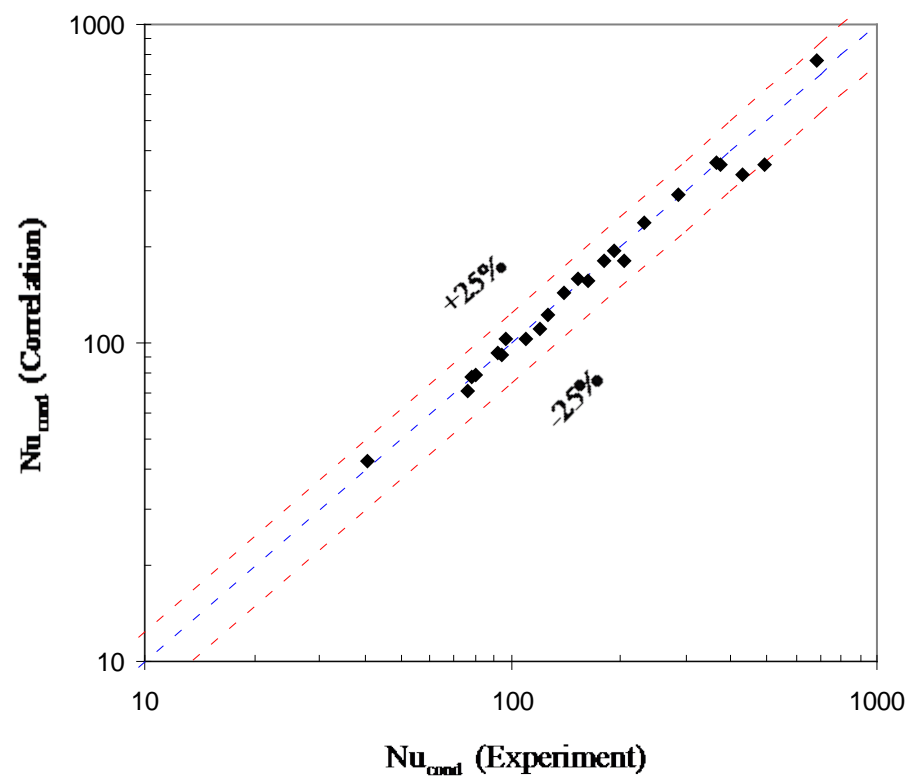

Fig. 7. Comparison between the experimental data and proposed correlation for the condensation heat transfer of refrigerant R-134a in the PHEs. 


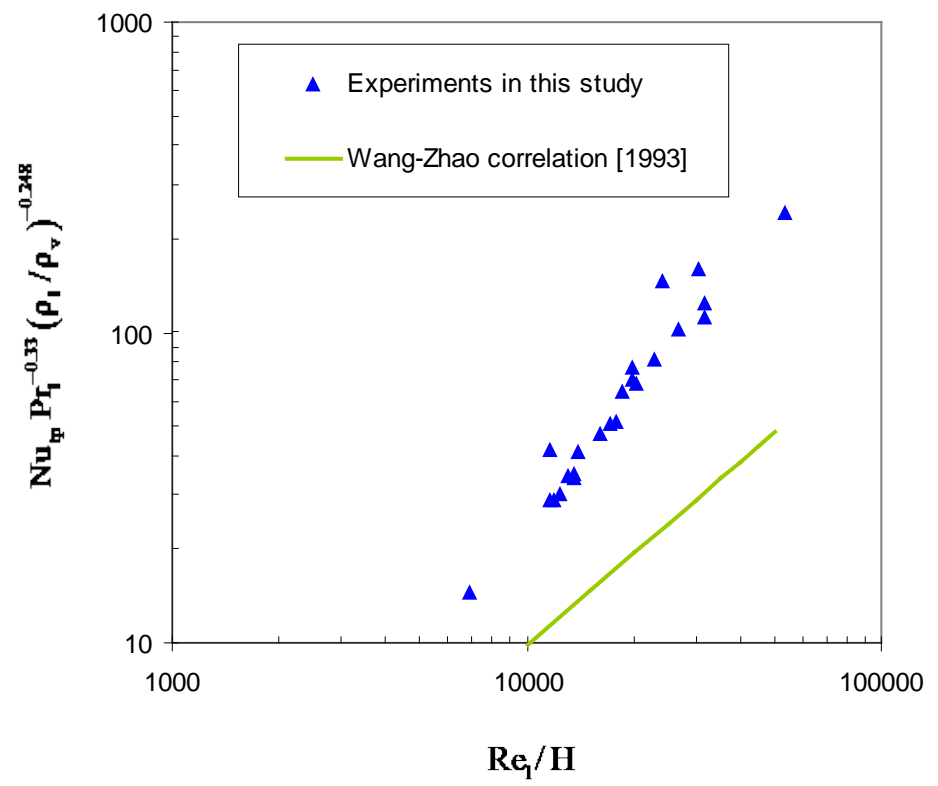

Fig. 8. Heat transfer correlations for the condensation of refrigerant R-134a in PHEs.

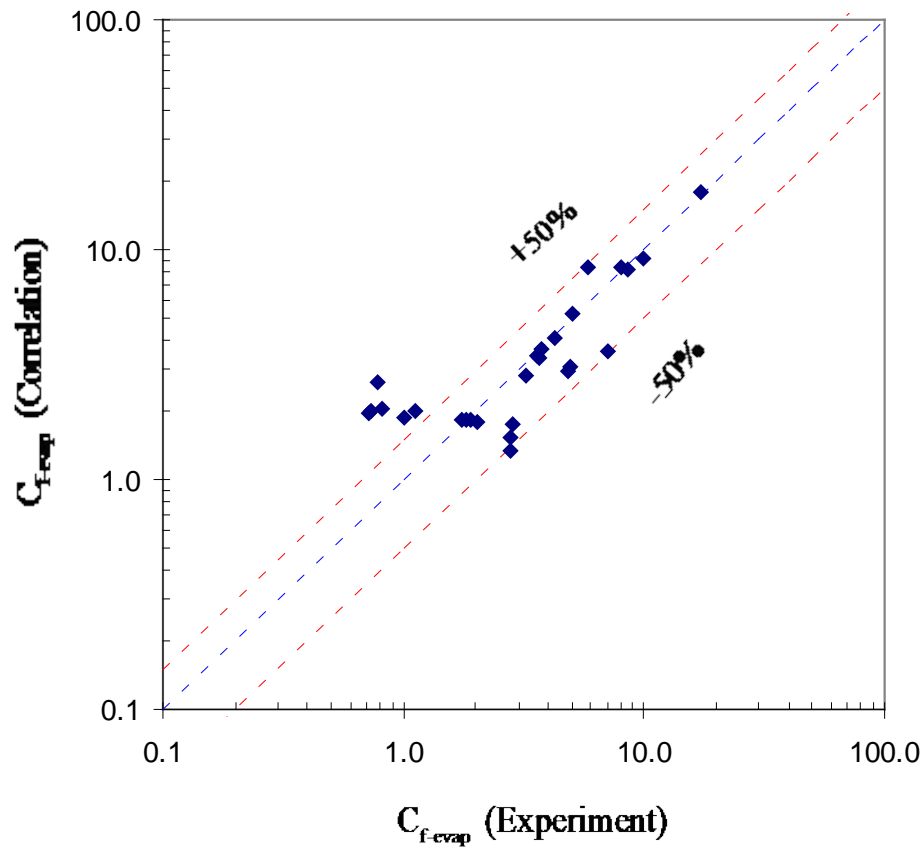

Fig. 9. Comparison between the experimental data and proposed correlation for the evaporation pressure drop of refrigerant R-134a in the PHEs. 


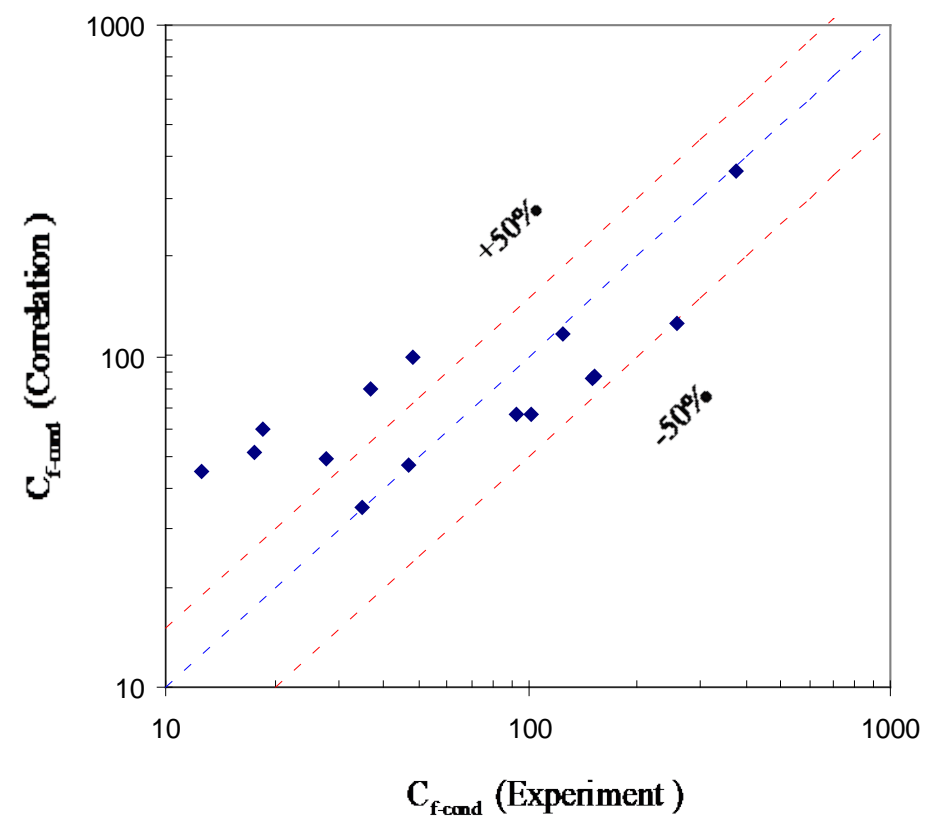

Fig. 10. Comparison between the experimental data and proposed correlation for the condensation pressure drop of refrigerant R-134a in the PHEs.

\section{Figures Caption}

Fig. 1. Schematic diagram of the experimental test facility.

Fig. 2. Counter-flow configuration of the refrigerant and glycol-water mixture within the PHEs.

Fig. 3. Temperature diagrams for the PHEs used as the evaporator and condenser.

Fig. 4. Uncertainty of the two-phase heat transfer coefficients for the refrigerant evaporation and condensation.

Fig. 5. Comparison between the experimental data and proposed correlation for the evaporation heat transfer of refrigerant R-134a in the PHEs.

Fig. 6. Heat transfer correlations for the evaporation of refrigerant R-134a in the PHEs.

Fig. 7. Comparison between the experimental data and proposed correlation for the condensation heat transfer of refrigerant R-134a in the PHEs.

Fig. 8. Heat transfer correlations for the condensation of refrigerant R-134a in PHEs.

Fig. 9. Comparison between the experimental data and proposed correlation for the evaporation pressure drop of refrigerant R-134a in the PHEs.

Fig. 10. Comparison between the experimental data and proposed correlation for the condensation pressure drop of refrigerant R-134a in the PHEs. 
Table 1

Geometry and size of the PHEs used in this study

\begin{tabular}{ll}
\hline Parameter & Measured/Calculated \\
\hline Plate area $\left(\mathrm{mm}^{2}\right)$ & 26,000 \\
Number of plates & 34,40 , and 54 \\
Height $(\mathrm{mm})$ & 311 \\
Width $(\mathrm{mm})$ & 112 \\
Plate thickness (mm) & 0.4 \\
Mean channel spacing (mm) & 2 \\
Corrugation inclination angle (degree) & 60 \\
Inlet/outlet port diameter (mm) & 30.5 \\
\hline
\end{tabular}

Table 2

The uncertainty of the measured and calculated parameters

\begin{tabular}{|c|c|c|}
\hline Parameter & Range in the tests & Uncertainty \\
\hline \multirow{4}{*}{ Temperature } & $\mathrm{T}_{\mathrm{g} \text {,evap }}\left(0\right.$ to $\left.30^{\circ} \mathrm{C}\right)$ & \multirow{4}{*}{ $\pm 0.2^{\circ} \mathrm{C}$} \\
\hline & $\mathrm{T}_{\mathrm{g}, \text { cond }}\left(29\right.$ to $\left.70^{\circ} \mathrm{C}\right)$ & \\
\hline & $\mathrm{T}_{\mathrm{r}, \text { evap }}\left(-6\right.$ to $\left.29^{\circ} \mathrm{C}\right)$ & \\
\hline & $\mathrm{T}_{\mathrm{r}, \text { cond }}\left(30\right.$ to $\left.120^{\circ} \mathrm{C}\right)$ & \\
\hline \multirow{2}{*}{ Pressure } & $\mathrm{P}_{\mathrm{r}, \text { evap }}(200$ to $600 \mathrm{kPa})$ & \multirow{2}{*}{ $\pm 1 \%$} \\
\hline & $\mathrm{P}_{\mathrm{r}, \text { cond }}(900$ to $2100 \mathrm{kPa})$ & \\
\hline Refrigerant mass flow rate & $m_{r, \text { evap }}=m_{r, \text { cond }}(0.01$ to $0.06 \mathrm{~kg} / \mathrm{s})$ & $\pm 0.2 \%$ \\
\hline \multirow{2}{*}{ Glycol-Water mass flow rate } & $\mathrm{m}_{\text {g,evap }}(0.13$ to $0.40 \mathrm{~kg} / \mathrm{s})$ & \multirow{2}{*}{ $\pm 1 \%$} \\
\hline & $\mathrm{m}_{\mathrm{g}, \text { cond }}(0.15$ to $0.45 \mathrm{~kg} / \mathrm{s})$ & \\
\hline Single-phase Fanning friction factor & $\mathrm{C}_{\mathrm{f}, \mathrm{g}}(0.7-2.4)$ & $\pm 4-7 \%$ \\
\hline Single-phase heat transfer coefficient & $\mathrm{h}_{\mathrm{g}}\left(500\right.$ to $\left.2500 \mathrm{~W} / \mathrm{m}^{2} . \mathrm{K}\right)$ & $\pm 5 \%$ \\
\hline Evaporator two-phase Fanning friction factor & $\mathrm{C}_{\mathrm{f}, \mathrm{tp} \text {-evap }}(1-18)$ & $\pm 4-48 \%$ \\
\hline Evaporator two-phase heat transfer coefficient & $\mathrm{h}_{\text {tp-evap }}\left(500\right.$ to $\left.2800 \mathrm{~W} / \mathrm{m}^{2} . \mathrm{K}\right)$ & $\pm 5-75 \%$ \\
\hline Condenser two-phase Fanning friction factor & $\mathrm{C}_{\mathrm{f}, \mathrm{tp}-\mathrm{cond}}(12-37)$ & $\pm 6-68 \%$ \\
\hline Condenser two-phase heat transfer coefficient & $\mathrm{h}_{\mathrm{tp}-\text { cond }}\left(700\right.$ to $\left.11000 \mathrm{~W} / \mathrm{m}^{2} . \mathrm{K}\right)$ & $\pm 5-65 \%$ \\
\hline
\end{tabular}

